\title{
Metformin IR versus XR Pharmacokinetics in Humans
}

\author{
Nasir Idkaidek ${ }^{1 *}$, Tawfiq Arafat ${ }^{1}$, Munther Melhim², Jaafar Alawneh² and Nancy Hakooz ${ }^{3}$ \\ ${ }^{1}$ University of Petra, Amman, Jordan \\ ${ }^{2}$ Jordan Center for Pharmaceutical Research (JCPR), Amman, Jordan \\ ${ }^{3}$ University of Jordan, Amman, Jordan
}

\begin{abstract}
Pharmacokinetics of metformin extended release (XR) formulation were studied under fasting and fed conditions and compared to those of immediate release (IR) under fasting conditions in humans. 78 healthy human volunteers participated in 3 independent studies (26 subjects per study) were given either $1000 \mathrm{mg}$ oral dose metformin IR or $750 \mathrm{mg}$ metformin XR. Plasma samples were obtained up to 24 hours after dosing. Pharmacokinetic parameters in plasma were calculated by non compartmental analysis using Kinetica program. Results have shown increased XR bioavailability and delayed time to reach the maximum concentration $\left(\mathrm{C}_{\max }\right)$ in the fed state as compared to fasted state, with no significant difference in $\mathrm{C}_{\max }$ and half life values. On the other hand, the IR formulation showed significant differences in all parameters as compared to XR formulation, yet the half life was similar. In conclusion, XR formulation was shown similar to IR formulation with less possible side effects.
\end{abstract}

Keywords: Metformin; Pharmacokinetics; Kinetica

\section{Introduction}

Metformin is an oral biguanide hypoglycemic agent. It causes an increased peripheral uptake of glucose by increasing the biological efficiency of available exogenous or endogenous insulin. The mode of action of metformin may be linked to an increase of insulin sensitivity. It does not stimulate insulin release but does require the presence of insulin to exert its hypoglycemic effect. Possible mechanisms of action include inhibition of gluconeogenesis in the liver, delay in glucose absorption from the gastrointestinal tract and an increase in peripheral uptake of glucose. After oral administration, metformin hydrochloride is absorbed along the entire gastrointestinal mucosa. After oral administration, metformin absorption is saturable and incomplete. It is assumed that the pharmacokinetics of metformin absorption is nonlinear. At usual clinical doses and dosing schedules of metformin tablets, steady state plasma concentrations are reached in 24 to 48 hours and are generally less than $1 \mu \mathrm{g} / \mathrm{mL}$. During controlled clinical trials, maximum metformin plasma levels did not generally exceed 5 $\mu \mathrm{g} / \mathrm{mL}$, even at maximum doses. However, therapeutic levels are 1-2 $\mu \mathrm{g} / \mathrm{mL}$. Metformin is excreted unchanged in the urine and does not undergo hepatic metabolism [1-5].

\section{Objectives}

The objective is to compare plasma pharmacokinetics of metformin extended release (XR) formulation studied under fasting and fed conditions and those of immediate release (IR) under fasting conditions in humans.

\section{Experimental}

\section{Study design}

78 healthy human volunteers participated in 3 independent parallel design studies (26 subjects per study). Subjects were given either 1000 $\mathrm{mg}$ oral dose metformin IR or $750 \mathrm{mg}$ metformin XR. Plasma samples were obtained up to 24 hours after dosing with 7 days washout time. The study was approved by IRB and Jordan FDA; and conducted by Jordan Center for Pharmaceutical Research at Al-Mowasah hospital as per the ICH, GCP and Helsinki declaration guidelines.

In the fast studies, After $10 \mathrm{hr}$ overnight fast, 1000 or $750 \mathrm{mg}$ oral dose of metformin tablet was given with $240 \mathrm{ml}$ water. While in the fed study dose was given directly after high fat breakfast: black olives (4 large), pita bread (3/4 of 6 inches across), 2 eggs (fried) with 3 tea spoon corn oil, 2 pieces of beef hotdog (fried) with 2 teaspoons corn oil, French fries (thin).

Blood samples were withdrawn at $0,0.33,0.66,1,1.33,1.66,2,2.5$, $3,3.5,4,4.5,5,5.5,6,8,10,12$ and $24 \mathrm{hr}$ post dose. Samples were deep stored at $-20^{\circ} \mathrm{C}$ until assayed by a validated HPLC method, with limit of quantization of $25 \mathrm{ng} / \mathrm{ml}$.

\section{Sample size determination}

Sample size was based on previous metformin highest intra-subject pharmacokinetic variability of $25 \%$ (unpublished JCPR data of IR formulation). The minimum sample size needed with $80 \%$ power and $95 \%$ confidence was 26 subjects per study.

\section{Human subjects}

78 male Adults were enrolled with age 18 to 50 years, body mass index 17.1 to $28.6 \mathrm{~kg} / \mathrm{m}^{2}$. Medical history, vital signs, physical examination, ECG and laboratory safety test results without evidence of clinically significant deviation from normal medical condition as evaluated by the clinical investigator. Subjects signed the Informed Consent Form before initiation of the study.

\section{Human medication}

Glucophage $1000 \mathrm{mg}$ tablet of Merck (Batch-No.: 112590, Expiry date: 02/2011) or 750mg XR tablet of Merck (Batch-No.: 591541, Ex Expiry date: 12/2011) were used.

*Corresponding author: Nasir Idkaidek, University of Petra, Pharmacy College PO Box 961343, Amman, Jordan, Tel: 96265715553; Fax: 96265715570; E-mail: nidkaidek@uop.edu.jo

Received September 15, 2011; Accepted November 02, 2011; Published November 04, 2011

Citation: Idkaidek N, Arafat T, Melhim M, Alawneh J, Hakooz N (2011) Metformin IR versus XR Pharmacokinetics in Humans. J Bioequiv Availab 3: 233-235. doi:10.4172/jbb.1000092

Copyright: @ 2011 Idkaidek N, et al. This is an open-access article distributed under the terms of the Creative Commons Attribution License, which permits unrestricted use, distribution, and reproduction in any medium, provided the original author and source are credited. 
Citation: Idkaidek N, Arafat T, Melhim M, Alawneh J, Hakooz N (2011) Metformin IR versus XR Pharmacokinetics in Humans. J Bioequiv Availab 3 : 233-235. doi:10.4172/jbb.1000092

\section{Assay methodology}

A high performance liquid chromatographic with \{Ultra Violet Detection $\}$ method for the determination of Metformin in human plasma has been validated using Cefadroxil as the internal standard. Sample preparation consisted of the addition of $0.20 \mathrm{ml}$ of plasma to $0.2 \mathrm{ml}$ of $5.0 \mu \mathrm{g} / \mathrm{ml}$ Cefadroxil monohydrate prepared in $5 \%$ Trichloroacetic Acid (T.C.A) in an Eppendorf, the mixture was vortexmixed for 60 seconds, then centrifuged for 5 minutes at $14000 \mathrm{rpm}$, then $0.20 \mathrm{ml}$ of the supernatant was transferred to flat bottom insert, then $50 \mu \mathrm{l}$ was injected on BDS Hypersil $\mathrm{C}_{18}$ Column. Metformin and the internal standard were separated from endogenous substances.

The mobile phase consisted of $91 \%$ of Water Contains $10 \mathrm{mM}$ Potassium dihydrogen phosphate buffer and $20 \mathrm{mM}$ 1-Hexanesulfonic Acid, Sodium Salt, $9 \%$ of Acetonitrile. $\mathrm{pH}=4.25$, adjusted with $\mathrm{H}_{3} \mathrm{PO}_{4}$. Detection of Metformin and the internal standard was achieved by using a UV Detector, $\lambda=234 \mathrm{~nm}$. The peak areas were measured and the ratio of Metformin to internal standard was calculated by the computer software. The relationship between concentration and peak area ratio was found to be linear within the range of 25.0 to 2500.0 $\mathrm{ng} / \mathrm{ml}$ for Metformin. The limit of quantification was $25.0 \mathrm{ng} / \mathrm{ml}$. The inter-day precision and accuracy of the determination of Metformin were determined before the start of the study using the data generated from both the Standard Curve and the Quality Control Samples.

From the Standard Curves, inter-day accuracy ranged from 96.87 - $104.59 \%$ and inter-day precision ranged from 0.83 - 5.81\%. From the Quality Control Samples, inter-day accuracy ranged from 100.76 $102.31 \%$ and inter-day precision ranged from $1.19-3.44 \%$. Data of the internal standard Cefadroxil $(6.0 \mu \mathrm{g} / \mathrm{ml})$ were stable during the analysis of the plasma samples of the volunteers which started at $\{22 / 06 / 2010\}$ and ended at $\{04 / 07 / 2010\}$, with mean (CV\%) of 3.92 (4.331\%).

\section{Data Analysis}

\section{Pharmacokinetic analysis}

Pharmacokinetic parameters for drug concentration were calculated by non-compartmental analysis (NCA) using Kinetica ${ }^{\mathrm{TM}}$ 2000 Computer Program. Pharmacokinetic parameters were area under the concentration curves to $24 \mathrm{hrs}$ and to infinity $\left(\mathrm{AUC}_{0 \rightarrow \mathrm{t}}\right.$ AUC $\left._{0 \rightarrow \infty}\right)$, Maximum measured plasma concentration \& its time $\left(\mathrm{C}_{\max }\right.$ $\left.\& \mathrm{~T}_{\max }\right)$, first-order elimination rate constant $\left(\mathrm{K}_{\mathrm{el}}\right)$ and half-life $\left(\mathrm{t}_{1 / 2}\right)$.

\section{Statistical analysis}

T-tests were performed, assuming normal distribution, on logtransformed pharmacokinetic parameters. $5 \%$ level of significance was used for all statistical comparisons.

\begin{tabular}{|l|l|l|l|l|}
\hline $\begin{array}{l}\text { Formulation / } \\
\text { Pharmacokinetic } \\
\text { parameter }\end{array}$ & XR-Fed & XR-Fasted & IR-Fasted & P-value \\
\hline $\mathrm{AUC}_{0 \rightarrow \mathrm{t}}(\mathrm{ng} \cdot \mathrm{mL} / \mathrm{hr})$ & $7143(1671)$ & $5795(2279)$ & $12459(3553)$ & $<0.05$ \\
\hline $\mathrm{AUC}_{0 \rightarrow \infty}(\mathrm{ng} \cdot \mathrm{mL} / \mathrm{hr})$ & $7448(1585)$ & $6167(2236)$ & $12884(3450)$ & $<0.05$ \\
\hline $\mathrm{C}_{\max }(\mathrm{ng} / \mathrm{mL})$ & $794(143)$ & $832(300)$ & $1956(476)$ & $<0.05$ * \\
\hline $\mathrm{t}_{1 / 2}(\mathrm{hr})$ & $3.66(0.8)$ & $3.8(1.2)$ & $3.39(0.7)$ & $>0.05$ \\
\hline $\mathrm{K}_{\mathrm{el}}(\mathrm{hr}-1)$ & $0.2(0.1)$ & $0.19(0.1)$ & $0.22(0.1)$ & $>0.05$ \\
\hline $\mathrm{T}_{\max }(\mathrm{hr})$ & $6.35(1.1)$ & $4.3(1.0)$ & $\begin{array}{l}2.58 \\
(1.0)\end{array}$ & $<0.05$ \\
\hline * $>0.05$ for XR-Fed vs XR-Fast C comparison & & \\
\hline
\end{tabular}

Table 1: Metformin mean (SD) plasma pharmacokinetic parameters after 1000 $\mathrm{mg}$ IR oral dose/ $750 \mathrm{mg} \mathrm{XR}$ oral doses to 78 healthy volunteers under different states.
Metformin Mean (SD) Plasma Concentrations

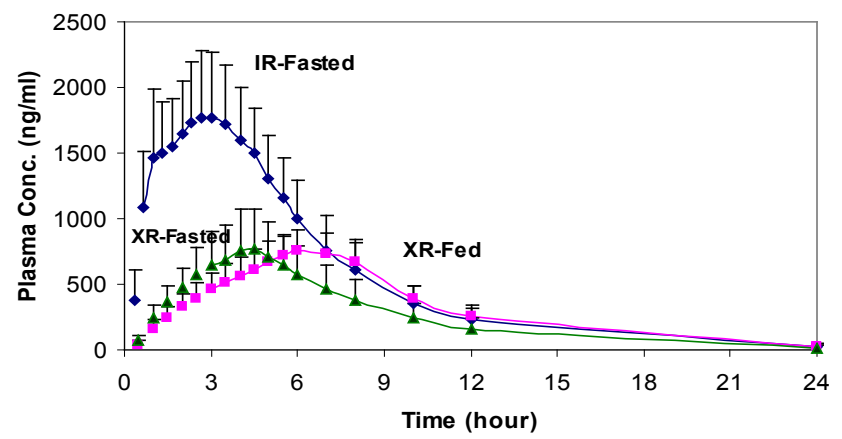

Figure 1: Metformin mean (SE) plasma levels $(\mathrm{ng} / \mathrm{mL}$ ) after $1000 \mathrm{mg} I \mathrm{R}$ ora dose/ $750 \mathrm{mg}$ XR oral doses to 78 healthy volunteers under different states.

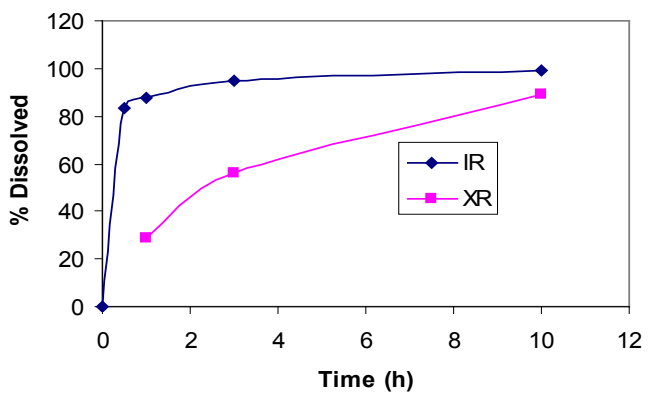

Figure 2: Metformin dissolution profiles of the IR (USP test II) and XR (USP test I) formulations in $0.1 \mathrm{~N} \mathrm{HCL}$.

\section{Results and Discussion}

Metformin mean (SD) pharmacokinetic parameters were presented in Table 1. Figure 1 shows mean plasma levels of metformin.

Results have shown increased XR bioavailability and delayed time to reach the maximum concentration $\left(\mathrm{C}_{\max }\right)$ in the fed state as compared to fasted state, with no significant difference in $\mathrm{C}_{\max }$ and half life values. On the other hand, the IR formulation showed significant differences in all parameters as compared to XR formulation, yet the half life was similar. In addition, they showed low variability and high statistical power $(>80 \%)$ indicating adequate study design.

On the other hand and from pharmacodynamic point of view, metformin therapeutic window is $1000-2000 \mathrm{ng} / \mathrm{ml}[2,3] . \mathrm{C}_{\max }$ mean value of $1956 \mathrm{ng} / \mathrm{ml}$ of IR formulation is close to the upper limit of 2000 $\mathrm{ng} / \mathrm{ml}$ and hence prone to increase above the upper limit at steady state. Indeed, 10 subjects had $\mathrm{C}_{\max }$ values above $2000 \mathrm{ng} / \mathrm{ml}$. However, $\mathrm{C}_{\max }$ mean values are close to the effective level of $1000 \mathrm{ng} / \mathrm{ml}$ and prone to fall within $1000-2000 \mathrm{ng} / \mathrm{ml}$ at steady state. This is consistent with the sustained release dissolution profile of the XR formulation as compared with the IR formulation as shown in Figure 2 (JCPR unpublished data). It takes 10 hours to reach more than $80 \%$ dissolution in the XR formulation (apparatus USP test II), while it took 30 minutes to reach 83.5\% dissolution in the IR formulation (apparatus USP test I).

This may explain the high dropout rate in patients taking IR formulation as compared to XR formulation, due to more side effects 
Citation: Idkaidek N, Arafat T, Melhim M, Alawneh J, Hakooz N (2011) Metformin IR versus XR Pharmacokinetics in Humans. J Bioequiv Availab 3: 233-235. doi:10.4172/jbb.1000092

such as gut disturbances in the IR formulation [4]. In deed and for XR formulation, 3 Subjects experienced 3 adverse events (headache, Diarrhea and vomiting). The most frequently reported adverse event was headache (3 Subjects). While for IR formulation, 4 subjects experienced 4 adverse events (abdominal pain, vomiting, dizziness and diarrhea). This is in agreement with previous studies that reported similar side effects after metformin IR and XR formulations; and also shown that metformin was well tolerated $[6,7]$.

\section{Conclusion}

Metformin IR formulation showed significant differences in all pharmacokinetic parameters as compared to XR formulation, yet the half life was similar. In conclusion, XR formulation was shown similar to IR formulation with less possible side effects.

\section{Acknowledgments}

This work was funded by Jordan Center for Pharmaceutical Research. We thank all medical staff at Al-Mowasah Hospital for their cooperation.

\section{References}

1. http://www.medsafe.govt.nz/profs/Datasheet/a/ArrowMetformintab.pdf
2. Dell'Aglio DM, Perino LJ, Kazzi Z, Abramson J, Schwartz MD, et al. (2009) Acute Metformin overdose: examination serum $\mathrm{pH}$, lactate level and metformin concentrations in survivors versus no survivals: a systematic review of the literature. Ann Emerg Med 54: 818-823.

3. Kazory A, Walsh K, Harman E, Talor Z (2007) Is metformin safe in patients with mild renal insufficiency? Diabetes Care 30: 444.

4. Schwartz S, Fonseca V, Berner B, Cramer M, Chiang YK, et al. (2006) Efficacy tolerability and safety of novel once-daily XR metformin in patients with type 2 diabetes. Diabetes Care 29: 759-763.

5. Najib N, Idkaidek N, Beshtawi M, Bader M, Admour I, et al. (2002) Bioequivalence evaluation of two brands of metformin $500 \mathrm{mg}$ tablets (Dialon \& Glucophage)--in healthy human volunteers. Biopharm Drug Dispos 23: 301 306.

6. Timmins P, Donahue S, Meeker J, Marathe P (2005) Steady-state pharmacokinetics of a novel extended-release metformin formulation. Clin Pharmacokinet 44: 721-729.

7. Gu N, Kim BH, Rhim H, Chung JY, Kim JR, et al. (2010) Comparison of the bioavailability and tolerability of fixed-dose combination glimepiride/metformin 2/500-mg tablets versus separate tablets: A single-dose, randomized-sequence, open-label, two-period crossover study in healthy Korean volunteers. Clin Ther 32:1408-18. 